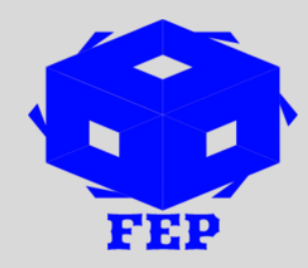

\title{
COMPARATIVE ANALYSIS OF FUTURE MARKET IN INDONESIAN CONTEXT
}

Surya Kalavathi ${ }^{1}$, Lenin Kanagasabai ${ }^{2}$

1,2, Gadjah Mada University, Indonesia

*Corresponding Author: Surya Kalavathi

Article Received: 18-09-19

Accepted: 16-01-20
Published: 05-02-20

Licensing Details: Author retains the right of this article. The article is distributed under the terms of the Creative Commons Attribution-Non Commercial 4.0 License (http://www.creativecommons.org/licences/by-nc/4.0/) which permits non-commercial use, reproduction and distribution of the work without further permission provided the original work is attributed as specified on the Journal open access page.

\begin{abstract}
For decision making, sugar basic identification can be used as a strategic tool. In this study, accessible forecast using ARMA $(\mathrm{p}, \mathrm{q})$ time series models comparing Indonesian sugar spot and ICE future markets. The study identified that in two cities of Indonesia, there exist synchronous high and low primary movement, and volatility with correlation coefficient of 0.70 , showing positive higher magnitude, and descriptive statistics. The result shows that in the selected two cities, Jakarta showed higher compare to the other city. Comparing forecasting errors between ARMA (p,q) and SARMAX (p,q) models, the monthly sugar basis model for Bande Aache is SARMAX (1,0). For Jakarta, the forecasted model is ARMA $(2,0)$. Additionally, the Bande Aache sugar basis breakpoint month is 2008M09 and for Bande Aache, breakpoint month is 2011M11. A closer analysis suggests that the breaking points coinciding with the identifiable sugar basis level and the volatility trends in the examined period. Both forecasted models are easier and implementable and can provide informational input for efficient allocative decisions by the Indonesian sugar supply chain.
\end{abstract}

Keywords: Forecast, Sugar Basis, Breakpoint, ARMA, SARMAX, Indonesia

\section{INTRODUCTION}

Indonesia is one of the agricultures producing country exporting sugar to many other countries. In fact, Indonesia expected to produce record 30 million tons of sugar annually. 
There is problem of sugar price variation which can cause loss to sugar market and hence there is need to understand the sugar price and market dynamics. For identifying whether the sugar price spikes are temporarily caused by demand supply mismatch or if there exist a permanent problem in sugar industry, there is need to evaluate the situation empirically and scientifically. Furthermore, due to the exporting sugar to international market, there is need to understand the sugar supply chain and exchange rates and its influence on sugar industry.

a strategic analytical variable for describing the fundamental dynamics of the Indonesian sugar price is the basis. In finance terms, the basis is the difference between spot and futures prices (Leuthold, Junkus, and Cordier, 1989). Mostly, the basis is presented in idiosyncratic pattern. It is also associated with convenience yields, risk premium, and commodity portfolio allocation. Basis is considered a relevant variable depending on agent's position in commodity supply chain. In sugar market, the agents need to identify the past and forecast the future trajectory of the basis. There are various variables influencing the Indonesian trajectory. In Indonesian market, the sugar market trajectory are influenced by various factors. There are several but seasonality is one of the major one along with convenience yield, storage cost, transportation, and volatility. Additionally, Indonesian sugar basis shows a significant role as a market sign of future macroeconomic expectations and productions, arbitrage opportunities, hedging, storage, trading, and production (Bailey \& Chan, 1993). Time series can be used for forecasting the Indonesian sugar basis market (Szymanowska, et al., 2014). For Indonesian sugar market, the constellation of autoregressive and moving average ARMA $(p, q)$ model with various input may compose robust forecasting techniques. In literature, there is no specific study investigating similar phenomenon.

\section{Objectives of the Study}

The objectives of the study are to formulate Indonesian sugar basis forecast using time series models comparing between northern and southern spot and ICE future markets.

\section{Significance of the Study}

The significance of the study is that it fills the literature gap in this domain. Furthermore, by comparing forecasting errors to estimate the most robust sugar basis time series model, we can increase the efficiency of allocation decision in Indonesian sugar supply chain.

\section{LITERATURE REVIEW}

Baseline risk for the S\&P 500 index future contracts, different sources are identified and studied (Figlewski, 1984). In this study, the conclusion was that non-systematic hedge of 
small portfolios and individual stock was relevant and that the maturity of more than two months affected hedge efficiency.

Another study by Pennings and Meulenberg (1997) conducted global risk reduction concept and measure of hedge efficiency by focusing on the future contract related hedging services. Their efficiency measure uses the basis risk, the market size, and the distance between the hedging efficiency of the future contract and the optimal hedge. The conclusion of the study is that the new measure created additional parameters for the efficient management of contracts on futures exchanges.

Frechette (2000) by utilizing the spatial-based risk, evaluated demand for hedge operations. The conclusion was that operating cost were negligible, and local hedging instruments were mitigating the basis risk which was increased in situation when demand for hedge was inelastic.

Another study investigated the optimal hedge model in terms of operating cost of the hedge. The conclusion of the study was that basis and expected risk estimates are dependent on a structure model which was used for the forecasting. The dependent model included different concepts such as rational expectations model, adaptive expectations model, and simple expectations model.

A study by Briys, Chouhy, and Schlesinger (1993) investigated the basis risks effects on hedging strategies. The study noted that because future contracts were incomplete, they were unable to provide partial hedging. The conclusion of the study was that basis risk can be split in to pure noise effects which could be analyzed as endogenous effect and residual noise.

Another study by Castelino (1992) showed that size of basis and different sources of risk were fundamental when choosing the optimal hedge instrument. The study also concluded that in situation of basis convergence occurred, the tendency was that optimal hedge rate towards the unit, the closer it got to maturity.

Dark (2007) investigated the magnitude of non-inclusion in the convergence specifications of the basis and long memory of volatility on dynamic optimal hedge rates. The conclusion of the study is that for long term maturity of the hedge, the convergence of the basis became more relevant. Additionally, convergence was important for short term hedges initiated close to maturity.

A study by Garcia, Leuthod, and Sahran (1984) investigated the short term basis risk which they define as temporal variance of the basis random component for the hogs and cattle. The study noted that basis risk was related to the factors which impacting the long term pattern of 
the time series and unforeseen price changes. The study found no evidence for the basis risk variation between market or with maturity.

A study by Leuthod and Peterson (1983) used system of equation for basis, spot prices, and future price for the Swine market and identified the relevance of the structural components such as storage.

A study by Jiang and Hayenga (1997) utilized structural approach for forecasting soybean and corn basis. the study concluded that in the short term, the complex models had better results, but in the long term, lower than the simple average.

Time series model is compared with simplified basis for predictions for moving averages for the soybean complex (Sanders and Manfredo, 2006). The study showed that sophisticated models showed better results compare to the simple one. A study by Tonsor, Dhuyetter, and Mintert (2004) investigated the number of annual lags for historical averages, combined with the optimal level of updated information for basis forecasting in livestock market. Another study by Hatchett, Brorsen, and Anderson (2009) investigated the optimal sizes of the historical average lags and showed less lags in comparison to other researchers. Conclusion of the study is that the a possible reason for reduced lags can be data structure related changes.

Dhuyvetter and Kastens (1998) analyzed historical averages and updated market information for predicting derivatives, maize, soybeans, and wheat. Analogously, short-term forecasts were improved by using more complex models which included updated information. However, better long-term forecasts were found based on historical averages. Another study by Sanders and Baker (2012) by utilizing soft transition regime model investigated the weekly forecasts of soy and corn basis. The study concluded that the soft transition regime model is suitable in terms of short term forecasts even though it lost efficiency for the simple moving average models in periods of higher volatility. Overall, the literature points out that there are different models for forecasting the basis but we did not come any specific study related to the sugar basis in Indonesian market.

\section{METHODOLOGY OF THE STUDY}

We used the methodology of the study by taking inspirations from Booth (2003). Details are as follows.

\section{ARMA Modelling for Basis Forecast}

ARMA (Autoregressive-moving average) modeling is utilized for forecasting the stationary time series. The ARMA (p, q) model composed of the sum of one autoregressive component, 
AR (p) and another of moving average, MA (q) is identified by using the Box, Jenkins, and Reinsel (2008a):

Stationarity of the ARMA (p, q) model requires fulfilling the necessary condition of stationarity. If a time series is stationarity, it indicate that the mean, the variance, and the autocorrelations can be approximated by sufficiently long-time averages based on a single set of observations. Generally, unit root test is used for testing the stationarity of a time series. The unit root operate under the hypothesis for identifying the ARMA model $(p, q)$ applicable to predictions, using the predictive efficiency criteria and parsimony criteria (Box, Jenkins, and Reinsel, 2008). The study used the unit root for the souther and northern time series. The criteria of adjusted R2, R2, Schwarz, and Akaie were used for selecting the $\operatorname{ARMA}(p, q)$ model. Furthermore, we tested the monthly seasonality of both basis including the significant months in a SARMAX (p, q) model. Finally, for evaluating the predictive efficiency of the ARMA model (p, q) we calculated MAE square root, and the square root of the mean absolute error; MAE the mean absolute error; PMAE the present MAE; and the symmetric PMAE. Error results between the ARMA (p, q) and SARMAX (p, q) models are compared for errors.

\section{Data}

The sugar monthly prices series were in US\$ per $50 \mathrm{~kg}$ bag:

i. for the Northern spot sugar market we used spot prices, applying a 0.54 multiply coefficient to approximate FOB prices since the internal market prices carry all direct and indirect tax burden;

ii. For the Southern spot sugar market we used spot prices;

iii. For the futures prices, we used ICE sugar \# 11

futures quotes; source: http://www.barchart.com/.

The study analysis period was between May 2002 to October 2017 making a total of 186 observations chosen in a non-probabilistic way for convenience and accessibility. Data accessibility justifies the chosen time period. The study period also include the 2008 financial crisis.

\section{RESULTS AND DISCUSSION}

Detailed analysis indicate that absolute movements with approximate synchronization of northern and southern VHP sugar spots and ICE \# sugar future prices. However, difference can be identified between future prices levels and sugar spots which primarily explains the 
sugar basis dynamics. We conclude that sugar basis forecast is strategic for Indonesia sugar market.

Next, dynamics of sugar basis between the norther and southern part is compared. Figure 2 indciate that the dynamics of the basis in the analyzed period. It is identified that there is synchronization between the higher and lower primary movements. Thus, narrowing and widening in sugar basis in Indonesian northern and southern part are convergent. We also observed strong volatility between the years of 2009 and 2011 which is coinciding with the peak sugar prices in 2011 and fall with subsequent stabilization.

Additionally, calculated correlation coefficient between the sugar basis of northern and southern part is 0.70 which explains higher positive magnitude and thus justifies synchronized dynamics. One possible reason for this can be the symmetry which exist between the sugar pricing processes in northern and southern part such as initial and final stocks, common marketing drivers, production, and consumption pattern. Table 1 provide the descriptive statistics for the sugar basis of northern and southern part.

Table 1

Descriptive statistics. Monthly sugar basis of VHP. Values in $R \$$ per $50 \mathrm{~kg}$ bag. Period: 2002M05 to 2017M10.

\begin{tabular}{lll}
\hline Statistics & BASIS_AL & BASIS_SP \\
\hline Average & -5.7723 & -2.2725 \\
Median & -5.5705 & -3.5009 \\
Maximum & 3.2902 & 5.3300 \\
Minimum & -35.0377 & -33.2752 \\
Standard-deviation & 2.377332 & 2.2575 \\
Asymmetry & -0.5523 & -3.3522 \\
Kurtosis & 2.3252 & 5.7570 \\
Jarque-Bera & 33.3572 & 372.7725 \\
Probability & 0.0027 & 0.0000 \\
Observations & 373 & 373 \\
\hline
\end{tabular}

The sugar basis of southern had the lowest mean median, minimum and maximum values. However, this area also shows greater asymmetry and distance from normality. The scale of production and sea freight structure can be one possible explanation for the higher values.

Further standard deviation and proxy for basis risk, registers the value of 3188 and 3259 for norther and southern part. Hence, we can say that there are insignificant difference between the sugar basis risks of the two regions.

For testing the unit root presence hypothesis in the time series, we used the Augmented Dickey-fuller model and the Phillips-Perron models. 
Table 2

Unit root tests (RU). Phillips-Perron (PP) and Augmented Dickey-Fuller $(A D F)$ test. Model with constant. Sugar basis. Monthly values in US\$ per 50 kg bag

\begin{tabular}{lll}
\hline Values & PP & \multicolumn{1}{c}{ ADF } \\
\hline \multicolumn{3}{c}{ Basis AL } \\
t-Statistic & $-3.5101^{*}$ & $-3.3380^{*}$ \\
Prob. & $\mathbf{0 . 0 0 0 3}$ & $\mathbf{0 . 0 0 0 5}$ \\
\multicolumn{3}{c}{ Basis SP } \\
t-Statistic & $-3.7151^{*}$ & $-5.8119^{*}$ \\
Prob. & $\mathbf{0 . 0 0 0 1}$ & $\mathbf{0 . 0 0 0 0}$ \\
\hline
\end{tabular}

The results as provided in the table 2 indicate that the hypothesis of the existence of unit root is rejected. Thus, the sugar basis series is registering stationarity and we can apply the technique of time series forecasting, ARMA. Monthly seasonality of the sugar basis is also utilized for identification of adjusted original ARMA model. The traditional forecast for both region sugar basis models resulted in SARMAX- Seasonal ARMA with Exogenous Input.

Table 3 provides the monthly seasonality of the both regions sugar basis. Table 3 indicates that the seasonality of the northern part is statistically significant in the months of January, February, June, and December. Additionally, there are statistically significant seasonality of the southern sugar basis in all months of the year starting from January to December. In return, the sugar basis shows significant seasonal coefficients for all months of the year.

Table 3

\begin{tabular}{lll}
\multicolumn{2}{c}{ Seasonality } & test of sugar basis. Mont \\
\hline \multicolumn{1}{c}{ Months } & Basis SP & Basis AL \\
\hline January & $-4.4624^{*}$ & $-7.2952^{*}$ \\
February & $-2.5522^{*}$ & $-7.5250^{*}$ \\
March & -0.9440 & $-4.9957^{*}$ \\
April & -0.5624 & $-4.2020^{*}$ \\
May & -0.4095 & $-4.9270^{*}$ \\
June & $-2.0246^{* *}$ & $-5.2925^{*}$ \\
July & $-2.5224^{*}$ & $-5.4947^{*}$ \\
August & $-2.4664^{*}$ & $-5.0745^{*}$ \\
September & $-4.2992^{*}$ & $-7.7092^{*}$ \\
October & $-4.4424^{*}$ & $-7.9797^{*}$ \\
November & $-2.6996^{*}$ & $-7.7725^{*}$ \\
December & $-4.2922^{*}$ & $-7.5222^{*}$ \\
\hline
\end{tabular}

Next, the ARMA model for the southern part sugar basis is identified, shown in Table 4: 
Table 4

Characterization of the ARMA model $(2,0)$ to forecast the monthly sugar basis. Spot prices for Southern Part and future prices of ICE

\begin{tabular}{lllll}
\hline & Coefficient & Standard Errors & Test-t & Prob. \\
\hline $\mathbf{C}$ & -2.2797 & 0.6560 & -3.3752 & 0.0006 \\
$\mathbf{A R}(\mathbf{1})$ & 1.0009 & 0.0537 & 19.2973 & 0.0000 \\
$\mathbf{A R}(\mathbf{2})$ & -0.2727 & 0.0353 & -6.0251 & 0.0000 \\
$\mathbf{R}^{2}$ & 0.6509 & Akaike info criteria & 3.1925 \\
Adjusted R $^{2}$ & 0.6350 & Schwarz info criteria & 3.2623
\end{tabular}

Table 4 provide ARMA $(2,0)$ with all coefficients statistically significant at $1 \%$. AR (1) shows strong positive magnitude providing underlining the autoregressivity of the series which is counterbalanced by the negative values of the AR (2) and the constant. The values of about 0.650 are recorded for the $\mathrm{R} 2$ and the adjusted $\mathrm{R} 2$ which indicate suitable model fitness. Table 5 provide the southern part SARMAX model.

The exogenous intervention analyzed the statistical significance of the elements of the original ARMA model $(2,0)$ including the monthly seasonality which is significant as provided in table 3 . Once seasonality is included, the constant was excluded. Table 5 provide the statistical magnitudes and $\operatorname{SARMAX}(2,0)$ elements significance. The Rsquare and adjusted Rsquare values improved about 5 units and reached to 0.680 resulting in relation to the $\operatorname{ARMA}(2,0)$ as reported.

Table 5

Characterization of the SARMAX model $(2,0)$ to forecast the monthly sugar basis. Spot prices and future prices of ICE

\begin{tabular}{lllll} 
& Coefficient & Standard Errors & Test-t & Prob. \\
\hline January & -2.5926 & 0.5920 & -4.6265 & 0.0006 \\
February & -1.5659 & 0.6246 & -4.4669 & 0.0010 \\
June & -1.5164 & 0.6419 & -2.5161 & 0.0054 \\
July & -2.4656 & 0.9466 & -2.5960 & 0.0060 \\
August & -2.2649 & 0.9440 & -2.5069 & 0.0056 \\
September & -4.1562 & 0.9629 & -4.5246 & 0.0004 \\
October & -4.1566 & 0.9504 & -4.6495 & 0.0004 \\
November & -2.4244 & 0.9511 & -2.4964 & 0.0146 \\
December & -2.9054 & 0.9496 & -2.9695 & 0.0046 \\
AR(1) & 0.9949 & 0.0666 & 14.944 & 0.0000 \\
AR(2) & -0.2421 & 0.0669 & -4.2621 & 0.0000 \\
$\mathbf{R}^{2}$ & 0.6929 & Akaike info criteria & & 4.1614 \\
Adjusted $\mathbf{R}^{2}$ & 0.6541 & Schwarz info criteria & 4.4611 \\
\hline
\end{tabular}


Table 6 compares the forecast errors between the ARMA $(2,0)$ and SARMAX $(2,0)$ models of the southern sugar basis:

Table 6

Comparison of forecast errors between the ARMA $(2,0)$ and SARMAX $(2,0)$ models of the Southern sugar basis. Forecast within the sample. Period 2015M11 and 2017M10, totaling 24 observations

\begin{tabular}{|c|c|c|c|c|c|c|}
\hline \multirow[b]{2}{*}{ Model } & \multirow[b]{2}{*}{ MAE Square $\operatorname{Root}^{1}$} & \multirow{2}{*}{$\mathbf{M A E}^{2}$} & \multirow{2}{*}{ PMAE ${ }^{3}$} & \multicolumn{2}{|c|}{ Theil Coefficient } & \multirow[b]{2}{*}{ Symmetric PMAE } \\
\hline & & & & Inequality & U2 & \\
\hline $\operatorname{ARMA}(2,0)^{\mathrm{a}}$ & 2.550 & 1.9525 & 299.8857 & 0.5285 & 0.7507 & 87.7089 \\
\hline $\operatorname{SARMAX}(2,0)^{\mathrm{b}}$ & 2.952 & 1.9752 & 557.5755 & 0.5151 & 0.9982 & 105.5178 \\
\hline Difference (b/a) & $20.7 \%$ & $1.7 \%$ & $12.7 \%$ & $-5.7 \%$ & $55.0 \%$ & $20.5 \%$ \\
\hline
\end{tabular}

The values of the MAE square root, PMAE, MAE, U2 coefficient, Theil's inequality and the symmetric PMAE of the ARMA $(2,0)$ and SARMAX $(2,0)$ models of the southern sugar basis are provided in the table 6. We found higher errors for SARMAX $(2,0)$ with the exception of Theil's inequality coefficient. However, the Rsquare and adjusted Rsquare of SARMAX (2.0) shows higher explanation in terms of unit compare to the ARMA $(2,0)$. By utilizing the model with the minimum errors, the application of the ARMA $(2,0)$ model was utilized for forecasting the southern sugar basis. As such, Figure 3 maps the results of the $\operatorname{ARMA}(2,0)$ forecast model and the dynamics of the residues:

A closer analysis shows that the fluctuation band of the ARMA $(2,0)$ model except between 2009 and 2011 coinciding the peak and fall in sugar prices. Therefore, in this period, it is possible to see an increase in basis volatility with convergence after the stabilization of sugar prices. Hence, the residuals coverage within the previous fluctuations band, indicating the applicability for the southern sugar basis using the ARMA $(2,0)$ model. In relation to the northern sugar basis, the ARMA $(1,1)$ model is identified in table 7 .

Table 7

Characterization of the ARMA model $(1,1)$ to predict the monthly sugar basis. Prices for São Paulo VHP and future prices of ICE

\begin{tabular}{lllll}
\hline Coefficient & Standard Errors & Test-t & Prob. & Coefficient \\
\hline $\mathbf{C}$ & -5.8205 & 0.8020 & -8.2924 & 0.0000 \\
AR(2) & 0.8824 & 0.0528 & 24.480 & 0.0000 \\
MA(2) & 0.2948 & 0.0854 & 2.8528 & 0.0088 \\
$\mathbf{R}^{2}$ & 0.8882 & Akaike info criteria & 4.0424 \\
Adjusted $\mathbf{R}^{\mathbf{2}}$ & 0.8802 & Schwarz info criteria & 4.2225 \\
\hline
\end{tabular}

The above table provide information about ARMA $(1,1)$ model which states that AR (1) and MA (1) coefficients are statistically significant. The results also shows higher level of positive magnitude of $\mathrm{AR}(1)$ term which is a sign of autoregressive of the Alagoas basis series. The Rsquare and Adjusted Rsquare also have higher values of .068 which shows 
higher level of fitness of the ARMA $(1,1)$ model for the sugar basis time series model. The next table provide details about the SARMAX model.

Table 8

Characterization of the SARMAX model $(1,0)$ model to predict the monthly sugar basis

\begin{tabular}{lcccl}
\hline & Coefficient & Standard Errors & Test-t & Prob. \\
\hline January & -7.173 & 1.0716 & -6.6775 & 0.0000 \\
February & -6.3971 & 1.0315 & -6.1970 & 0.0000 \\
March & -3.7350 & 0.9373 & -5.0077 & 0.0000 \\
April & -3.0316 & 0.9666 & -3.1719 & 0.0000 \\
May & -3.6191 & 1.0791 & -3.3131 & 0.0011 \\
June & -5.0395 & 1.0159 & -3.9117 & 0.0000 \\
July & -5.3561 & 0.9333 & -5.7733 & 0.0000 \\
August & -5.0119 & 0.7931 & -5.6167 & 0.0000 \\
September & -6.6600 & 0.9313 & -7.1331 & 0.0000 \\
October & -6.9116 & 1.0077 & -6.7679 & 0.0000 \\
November & -6.5717 & 1.1600 & -5.6663 & 0.0000 \\
December & -7.3130 & 1.1133 & -6.6513 & 0.0000 \\
\hline AR(1) & 0.8319 & 0.0338 & 19.1135 & 0.0000 \\
R $^{1}$ & 0.8516 & Akaike info criteria & & 3.9188 \\
Adjusted R & 0.8316 & Schwarz info criteria & & 3.1613 \\
\hline
\end{tabular}

Original ARMA $(1,1)$ model exogeneous intervention is examined statistically based on monthly seasonality. The constant and the MA (1) term were excluded after the inclusion of the seasonality. The resulting model's magnitude and significance level is presented in the next table. The result shows that SARMAX $(1,0)$ was better explaining the variation compare to the ARMA $(1,1)$ as we observed improvement in the Rsquare value. Next table compares the forecast errors between the ARMA $(1,1)$ and SARMAX $(1,0)$ models of the sugar basis:

Table 9

Comparison of prediction errors between the ARMA $(1,1)$ and SARMAX $(1,0)$ models of the sugar basis. Forecast within the sample. Period 2015 M11 and 2017M10, totaling 24 observations

\begin{tabular}{|c|c|c|c|c|c|c|}
\hline \multirow[b]{2}{*}{ Model } & \multirow[b]{2}{*}{ MAE Square Root ${ }^{1}$} & \multirow{2}{*}{$\mathbf{M A E}^{1}$} & \multirow{2}{*}{ PMAE $^{4}$} & \multicolumn{2}{|c|}{ Theil Coefficient } & \multirow[b]{2}{*}{ Symmetric PMAE ${ }^{4}$} \\
\hline & & & & Inequality & U1 & \\
\hline $\operatorname{ARMA}(1,1)^{\mathrm{a}}$ & 1.3015 & 1.8138 & 16.6838 & 0.1855 & 1.3111 & 18.1866 \\
\hline $\operatorname{SARMAX}(1,0)^{b}$ & 1.1831 & 1.6111 & 13.9919 & 0.1669 & 1.3091 & 13.6808 \\
\hline Difference (b/a) & $-5.1 \%$ & $-10.6 \%$ & $-10.1 \%$ & $-3.9 \%$ & $-0.1 \%$ & $-9.1 \%$ \\
\hline
\end{tabular}

The above table indicate the values of the MAE square root, PMAE, MAE, U2 coefficients, Theil's inequality, and the symmetric PMAE of the ARMA $(1,1)$ and $\operatorname{SARMAX}(1,0)$ which forecast the sugar basis. As compare to the ARMA $(1,1)$ model, SARMAX $(1,0)$ shows better results in terms of reduced forecasting errors. Hence, we can say that by 
applying the criterion of use of the minimum errors, the SARMAX $(1,0)$ model can be chosen to forecast the sugar basis.

The analysis indicates that the residual bandwidth of the $\operatorname{SARMAX}(1,0)$ model which is uniformly distributed except between the year 2009 and year 2011 coinciding with the peak and fall in sugar prices. The results are similar to the previous figure which is related to the ARMA $(2,0)$ model residues for the southern sugar basis forecast model. During this period, the increase in basis volatility was highlighted with the convergence after the stabilization of sugar prices. Hence, the residuals coverage again within the previous fluctuations band, pointing to the forecasting applicability of the sugar basis using the $\operatorname{SARMAX}(1,0)$ model.

The dates of the monthly breaks of the sugar basis series of norther and southern part is identified using the Quandt-Andrews test for structural breaks.

Table 10

Quandt-Andrews test for unknown structural breaks1. Dates of the breaks of the sugar basis series of northern and southern part. Period: 2002M05 to 2017M10.

\begin{tabular}{lllll}
\hline Sugar basis & Structural break month & Quandt-Andrews statistics & Value & p-value \\
\hline \multirow{2}{*}{ Northern } & $2008 \mathrm{M} 09$ & $\begin{array}{l}\text { Maximum LR F-statistic } \\
\text { Maximum Wald }\end{array}$ & 96.6403 & 0.0000 \\
& & $\begin{array}{l}\text { F-statistic } \\
\text { Maximum LR }\end{array}$ & 96.6403 & 0.0000 \\
Southern & $2011 \mathrm{M} 11$ & $\begin{array}{l}\text { F-statistic } \\
\text { Maximum Wald }\end{array}$ & 11.0480 & 0.0162 \\
& & F-statistic & 11.0480 & 0.0162 \\
\hline
\end{tabular}

2008M09 and 2011M11 are indicated for the structural breaks in the sugar basis series of northern and southern part respectively. The dates are in coinciding with the sugar price volatility increases. These increase in volatility of the residues dynamics is expressed in relevant figures.

In summary, the forecast of southern and northern spot and ICE \# 11 sugar monthly basis indicate different models classified by the error minimization criteria. ARMA $(2,0)$ model can be used for forecasting the northern sugar monthly basis. In sum, the ARMA and SARMAX models formulate a strategic mechanism for assessing the Indonesian sugar basis relative to ICE sugar 11 futures.

\section{SUMMARY AND CONCLUSIONS}

Sugar basis identification can be a strategic tool for making efficient decisions by the sugar supply chain agents of Indonesia. The study identified the significant ARMA (p, q) model for forecasting the montly Indonesian regional sugar basis. Basis seasonality patterns is chosen for best fit SARMAX ( $\mathrm{p}, \mathrm{q})$ model. The study identifies that for sugar basis in northern and southern part, there is synchronous movement with higher level of volatility. 
We also found a strong positive correlation of 0.70 between both sugar basis showing a positive magnitude and confirming the cross-effects between both region sugar basis. the data is stationary at I (0) for both regions. More specifically, northern sugar basis indicate seasonality for all year around; whereas, southern part basis shows seasonality for nine months. This knowledge of sugar basis seasonality can be used for improved decision making by supply chain agents. By comparing sugar basis in sample forecasting errors between ARMA (p, q) and SARMAX (p, q) models, northern monthly sugar basis robust forecast model is a SARMAX $(1,0)$. For the southern monthly sugar basis, the robust forecast model is an ARMA $(2,0)$. The breaking point month for northern part sugar basis is 2008M09; while, for southern part sugar basis breakpoint month is 2011M11. The breakpoint months coincide with the identifiable sugar basis level and volatility trends abnormal trajectory in the examined period. Hence, it can be argued that ARMA (p, q) time series model can be used as a strategic decision making tool.

\section{References}

Bailey, K., Warren, M., \& Chan. K.C. (1993). Macroeconomic Influences and the Variability of the Commodity Futures Basis. The Journal of Finance, 48(2). https://doi.org/10.1111/j.1540-6261.1993.tb04727.x.

Booth, K., \& Wayne C. (2003). The Craft of Research. Linear Algebra and Its Applications, 422. https://doi.org/10.1016/j.laa.2006.10.019.

Box, K., George, E. P., Gwilym, M., Jenkins, K., Gregory, C., \& Reinsel. (2008). Time Series Analysis: Forecasting and Control. John Wiley.

Briys, K., Eric, M., Crouhy, M., \& Schlesinger, H. (1993). Optimal Hedging in a Futures Market with Background Noise and Basis Risk. European Economic Review 37(5). 949-60. https://doi.org/10.1016/0014-2921(93)90103-H.

Castelino, K., \& Mark, G. (1992). Hedge Effectiveness: Basis Risk and Minimum variance Hedging. Journal of Futures Markets, 12(2), 187-201. https://doi.org/10.1002/fut.3990120207.

CEPEA. (2016). Centro de Estudos Avançados Em Economia Aplicada. Imagenet Tecnologia. 2016. https://www.cepea.esalq.usp.br/br.

Dhuyvetter, K., Kevin, C., \& Terry, L., \& Kastens. (1998). Forecasting Crop Basis : Practical Alternatives. http://www.farmdoc.uiuc.edu/nccc134].

Dickey, K., David, A., \& Wayne, A., \& Fuller. (1979). Distribution of the Estimators for Autoregressive Time Series With a Unit Root. Journal of the American Statistical Association, 74(366). 427. https://doi.org/10.2307/2286348.

European Commission. (2009). Perspectives and evaluations Directorate L. Economic analysis, and L.5. Agricultural trade policy Analysis. 2009. "Historical Price Volatility.” https://ec.europa.eu/agriculture/trade-analysis_en. 
Frechette, D., \& Darren, L. (2000). The Demand for Hedging and the Value of Hedging Opportunities. American Journal of Agricultural Economics, 82(4), 97-907. https://doi.org/10.1111/00029092.00089.

Hatchett, K., Robert, B., Brorsen, B., Kim, B., \& Anderson. (2009). Optimal Length of Moving Average to Forecast Futures Basis. Journal of Agricultural and Resource Economics, 35, 18-33. https://doi.org/10.2307/23243034.

Jiang, K., Bingrong, M., \& Hayenga, M. (1997). Corn and Soybean Basis Behavior and Forecasting : Fundamental and Alternative Approaches by Bingrong Jiang and Marvin Hayenga, no. June 2003. http://lib.dr.iastate.edu/rtd.

Jonathan, D. (2007). Basis Convergence and Long Memory in Volatility When Dynamic Hedging with Futures. Journal of Financial and Quantitative Analysis, 42(04), 1021. https://doi.org/10.1017/S0022109000003483.

Pennings, J., Joost, M.E., Matthew, T.G., Meulenberg. (1997). Hedging Efficiency: A Futures Exchange Management Approach. Journal of Futures Markets 17(5), 599615. https://doi.org/10.1002/(SICI)1096-9934(199708)17:5<599::AIDFUT5>3.0.CO;2-A.

Philip, G., Leuthold, K., \& Sarhan, K.M. (1984). Basis Risk: Measurement and Analysis of Basis Fluctuations for Selected Livestock Markets. Agricultural \& Applied Economics Association, 66 (4), 499-504. https://doi.org/10.2307/1240929.

Phillips, P. C. B., \& Perron, P. (1988). Testing for a Unit Root in Time Series Regressions. Biometrika, 75(2), 335-46. https://doi.org/10.2307/2336182.

Sanders, D. J., \& Baker, T.G. (2012). Forecasting Corn and Soybean Basis Using RegimeSwitching Models

By. https://pdfs.semanticscholar.org/bbbb/05e258fcc31703c65c2c70f308eed05941b1.pdf.

Sanders, D. R., \& Manfredo, M.R. (2006). Forecasting Basis Levels in the Soybean Complex: A Comparison of Time Series Methods. Journal of Agricultural and Applied Economics, 38(03), 513-23. https://doi.org/10.1017/S1074070800022586.

Stephen, F. (1984). Hedging Performance and Basis Risk in Stock Index Futures. The Journal of Finance, 39(3), 657. https://doi.org/10.2307/2327924.

Walter, E. (2010). Applied Econometric Time Series. Wiley. 